\title{
Effect of Intensity Modulated Radiotherapy (IMRT) on the immunity, physical status and clinical effect of locally advanced NSCLC patients
}

\author{
Jun-kai Xu
}

\begin{abstract}
Objectives: To evaluate the clinical value of radiotherapy combined with Camrelizumab in treating locally advanced non-small cell lung cancer (NSCLC) patients.

Methods: 80 locally advanced NSCLC patients were randomly divided into two groups $(n=40)$. The control group was administered with intensity modulated radiation therapy (IMRT), whereas the experimental group with Camrelizumab in addition to IMRT. All the patients underwent clinical efficacy evaluation in terms of adverse drug reaction (ADR), physical status improvement after the treatment, and changes in $T$ lymphocyte subpopulations (incl. $\mathrm{CD} 3^{+}, \mathrm{CD}^{+}, \mathrm{CD}^{+}, \mathrm{CD}^{+} / \mathrm{CD} 8^{+}$).

Results: The efficacy was found to be $70 \%$ and 47.5 in experimental group and control group, respectively, with the former being significantly better than the latter $(p=0.03)$. The ADR rates were $50 \%$ and $37.5 \%$ in the experimental group and control group, respectively; but the difference remained insignificant $(p=0.26)$. As for physical status improvement, experimental group evidently excelled the control group $(p=0.04)$. The post-treatment indicators such as $\mathrm{CD}^{+}, \mathrm{CD}^{+}, \mathrm{CD}^{+}, \mathrm{CD}^{+} / \mathrm{CD}^{+}$were significantly more improved in the experimental group than the control group $\left(\mathrm{CD3}^{+}, \mathrm{p}=0.02\right.$; $\mathrm{CD}^{+}, \mathrm{p}=0.00$; and $\left.\mathrm{CD} 4^{+} / \mathrm{CD} 8^{+}, \mathrm{p}=0.01\right)$. However, the changes in CD8+ were not significant at all $(p=0.46)$.

Conclusions: The combined therapy of IMRT with Camrelizumab appeared effective in dealing with the locally advanced NSCLC patients, as such patients presented significantly better immune state and physical status improvement but not increased ADR. The therapy is both safe and effective.
\end{abstract}

KEYWORDS: IMRT, Camrelizumab, Locally advanced, NSCLC, Treatment.

doi: https://doi.org/10.12669/pjms.37.5.4188

How to cite this:

Xu JK. Effect of Intensity Modulated Radiotherapy (IMRT) on the immunity, physical status and clinical effect of locally advanced NSCLC patients. Pak J Med Sci. 2021;37(5):1480-1485. doi: https://doi.org/10.12669/pjms.37.5.4188

This is an Open Access article distributed under the terms of the Creative Commons Attribution License (http://creativecommons.org/licenses/by/3.0), which permits unrestricted use, distribution, and reproduction in any medium, provided the original work is properly cited.

1. Jun-kai Xu

Department of Radiotherapy,

The Affiliated Hospital (Group) of Putian University,

Putian, 351100,

P.R. China.

Correspondence:

Jun-kai Xu,

Department of Radiotherapy,

The Affiliated Hospital (Group) of Putian University,

Putian, 351100,

P.R. China.

E-mail: jiaowo310831@163.com

* Received for Publication:

* Edited and Corrected:

* Accepted for Publication: *

January 12, 2021

April 20, 2021

April 28, 2021

\section{INTRODUCTION}

Lung cancer is the most common cancer as well as the first leading cause of death around the world. ${ }^{1}$ Among all types of lung cancer, NSCLC accounts for the majority. ${ }^{2}$ Affected by a string of factors like environment and life pressure, lung cancer morbidity grows year by year, posing a great threat to the health of patients. ${ }^{3}$ For locally advanced lung cancer patients, a common therapy is radiotherapy that destroys cancer cells in virtue of direct harm from radioactive rays. The radioactive range must be large enough to include the cancer cells within the field, which also brings in effect on the normal tissues and organs around the tumor. The resulting 
radioactive damage and dysfunction is so significant that undermines the patients' life. IMRT is an emerging approach of radiotherapy in recent years, which essence lies in defining different tumor zones and administrating radioactive dosage accordingly. Therefore, this therapy is less damaging than traditional radiotherapy. Clinical evidence shows IMRT can significantly better improve patients' life quality when compared with traditional radiotherapy. ${ }^{4}$ For locally advanced NSCLC patients, multimodal therapies such as radiotherapy and other systemic therapies stand out in therapeutic effect. ${ }^{5}$ Researches have suggested target treatment and immunotherapy ${ }^{6}$ may improve the general survival rate of metastatic NSCLC patients. As a kind of immunotherapeutic drug, PD-1 has been applied to the clinical treatment of NSCLC patients, ${ }^{7}$ which could restore cell's immunity via specifically blocking PD-1 suppression pathway and thus inhibit the tumor cells. ${ }^{8}$ We treated locally advanced NSCLC patients with IMRT combined with Camrelizumab and witnessed certain clinical efficacy of the combined therapy on such patients. The combined therapy revealed certain strengths in improving the patients' immunity, physical status and clinical efficacy. Now the findings of our study are reported hereby.

\section{METHODS}

Ethical approval: The study was approved by the Institutional Ethics Committee of The Affiliated Hospital (Group) of Putian University, and written informed consent was obtained from all participants.

1. NSCLC patient ${ }^{9}$ (diagnosed with puncture or surgical specimens

2. Clinical staging $\geq \mathrm{III}^{10}$ (locally advanced.

3. Focus on imaging examination of chest (CT or MRI) with an accurately evaluated size ${ }^{11}$.

4. Permission and compliance from patients or their family members.

5. Inability to finish the study due to allergy to the drug or intolerance to the therapy involved in this study.

6. Those who signed informed consent.

Exclusion criteria:

1. Patients with unideal constitution, unstable vital signs, and intolerance to the treatment.

2. Patients with complicating malignant tumor in other systems.

3. Combined severe underlying disease.

4. Inability to finish the experiment due to mental, neurological or other reasons.
5. Taking hormone or immunosuppressor recently.

Altogether 80 locally advanced NSCLC patients admitted into our hospital recently were randomly divided into two groups $(n=40)$. The experimental group included 27 male cases and 13 female ones with an average age of $59.47 \pm 11.28$ years old (range: 45 73 years old); while the control group contained 25 male cases and 15 female ones with an average age of $58.11 \pm 10.74$ years old (range: 43 70 years old). Patients in the two groups weren't significantly different in general data and remained comparable (Table-I).

All the patients were administered with IMRT. Before receiving the radiotherapy, patients received a non-contrast scan and contrast scan of chest. Based on Pinnacle $38.0 \mathrm{~m}$ treatment plan system, clinical target volume (CRV) was sketched on their CT images as specified by the International Commission on Radiation Units and Measurements (ICRU). ${ }^{12}$ The CRV included Gross Tumor Volume (TGV) (lung tumor shadow area displayed on CT), GTV of positive mediastinal lymph nodes (GTVnd) (mediastinal enlarged lymph nodes), Clinical Tumor Volume (GTV) $(5-10 \mathrm{~mm}$ enlarged beyond GTV to include the whole lymphatic drainage area where metastatic lymph nodes are as confirmed by imaging results), Planned Tumor Volume (PTV) (5mm beyond the CTV), Planned Gross Tumor Volume $(5 \mathrm{~mm}$ directly beyond the tumor mass), and Planned Gross Tumor Volume of Metastatic Lymph Nodes (PGTVnd) (5mm beyond the GTVnd). IMRT dosage ${ }^{13}$ 1. PTV: 1.8-2.0Gy/per cycle, 30 cycles in total, total dosage: 54-60 Gy; 2. PGTVnd: 2.0-2.3 Gy/per cycle, 30 cycles in total, total dosage: 60-69 Gy; and 3. PGTV: 2.1-2.5Gy/per cycle, 30 cycles in total, total dosage: $63-75 \mathrm{~Gy}$.

The control group was administered with IMRT alone, while the experimental group was also intravenously administered with Camrelizumab at $200 \mathrm{mg} /$ per time within 30-60min and once every two weeks until the disease no longer proceeded or intolerable toxicity was observed.

1) Clinical efficacy evaluation: all the patients were assessed in accordance with Response Evaluation Criteria in Solid Tumors 1.0 (RECIST1.0) $^{14}$ as follows: Complete Response (CR): all target lesions gone; Partial Response (PR): $\geq 30 \%$ decrease of target's total measured radius from baseline; Stable Disease (SD): decrease of longest radius of focus by $25-50 \%$; Progressive Disease (PD) ( $\geq 20 \%$ increase from the smallest sum of longest diameter recorded since treatment started, and absolute increase of 
total longer radius by over $5 \mathrm{~mm}$; or appearance of new focus); and overall response rate $=(\mathrm{CR}+\mathrm{PR})$ case/ total cases $\times 100 \%$. (2) ADR evaluation: the adverse drug reactions of patients in two groups within 1 month after drug administration were recorded, including anemia, fever, WBC decrease, radiation pneumonia, cough, and poor appetite. (3) Physical status score: ECOG scoring ${ }^{15}$ was employed to assess the changes in physical status before and after the treatment. There were three categories, namely improved (score decrease $\geq 1$ ), stable (score unchanged) and deteriorating (score increase $\geq 1$ ). (4) Immunity analysis: fasting blood was collected in the mornings before and after the treatment to detect the levels of $\mathrm{T}$ lymphocyte subpopulations $\mathrm{CD}^{+}, \mathrm{CD}^{+}, \mathrm{CD}^{+}$, and $\mathrm{CD} 4^{+} / \mathrm{CD} 8^{+}$ and comparatively analyze the difference between patients in two groups before and after receiving the treatment.

Statistical Analysis: The statistical analysis of all data was done using SPSS 20.0 software. Measurement data were expressed as $\pm S$. Intergroup analysis was carried out with an independent-sample $\mathrm{T}$ test while intragroup analysis with a pair $\mathrm{T}$ test. Rate comparison was checked with. The difference was considered as significant when $\mathrm{P}<0.05$.

\section{RESULTS}

The patients in the two groups weren't significantly different from each other in levels of $\mathrm{CD}^{+}, \mathrm{CD}^{+}, \mathrm{CD}^{+}$and $\mathrm{CD} 4^{+} / \mathrm{CD}^{+}(\mathrm{p}>0.05)$ before the treatment started. After the treatment was finished, levels of $\mathrm{CD}^{+}, \mathrm{CD}^{+}, \mathrm{CD}^{+}$and $\mathrm{CD} 4^{+} /$ $\mathrm{CD}^{+}$in the experimental group were significantly higher than that in the control group $\left(\mathrm{CD}^{+}, \mathrm{p}=0.02\right.$; $\left.\mathrm{CD}^{+}, \mathrm{p}=0.00 ; \mathrm{CD}^{+} / \mathrm{CD}^{+}, \mathrm{p}=0.01\right)$. By contrast, the changes in $\mathrm{CD} 8+$ remained insignificant $(p=0.46)$ (Table-II). The experimental group presented a significantly higher physical status score improvement rate than the control group $(p=0.04)$, as the patients in this group experienced a better improvement in the physical status (Table-III).

Table-IV compares the therapeutic effect on patients of two groups, suggesting the posttreatment overall response rate of experimental group is $70 \%$ while that of the control group is only $47.5 \%$. The experimental group was significantly superior to the control group in this respect $(p=0.04)$.A comparative analysis of ADR rates in two groups after the treatment reveals the ADR rate in the experimental group is $50 \%$ and that in the control group is $37.5 \%$. Regardless of the higher ADR rate in the experimental group, intergroup difference is insignificant $(p=0.26)($ Table-V).

\section{DISCUSSION}

NSCLC is the most common pathological type in lung cancer, accounting for $85 \%$ of newly diagnosed lung cancer cases. Its 5-year survival rate ranges from $92 \%$ in early stage to $13 \%$ in advanced stage. ${ }^{16}$ Radiotherapy is frequently used to treat locally advanced NSCLC. Nevertheless, even if receiving the radiotherapy, such patients still have a low survival rate. Studies indicate ${ }^{17}$ clinical control rate among NSCLC patients that have received

Table-I: A comparative analysis of the experimental group with control group in general data $(\bar{X} \pm S) n=40$.

\begin{tabular}{lcccc}
\hline Indicator & Experimental Group & Control Group & $t / \chi^{2}$ & $P$ \\
\hline Age (year) & $59.47 \pm 11.28$ & $58.11 \pm 10.74$ & 0.55 & 0.58 \\
Male (ratio \%) & $27(67.5 \%)$ & $25(62.5 \%)$ & 0.22 & 0.64 \\
Pathological pattern & & & \\
Adenocarcinoma & $21(52.5 \%)$ & $22(55 \%)$ & 0.05 & 0.82 \\
Squamous cancer & $15(37.5 \%)$ & $13(32.5 \%)$ & 0.22 & 0.64 \\
Others & $4(10 \%)$ & $5(12.5 \%)$ & 0.13 & 0.72 \\
Location of tumor & & & & \\
Peripheral & $25(62.5 \%)$ & $23(57.5 \%)$ & 0.21 & 0.65 \\
Central & $15(37.5 \%)$ & $17(42.5 \%)$ & 0.20 & 0.64 \\
Clinical stage & & & & 0.22 \\
III & $27(67.5 \%)$ & $25(62.5 \%)$ & 0.64 \\
IV & $13(32.5 \%)$ & $15(37.5 \%)$ & 0.26 & 0.59 \\
\hline
\end{tabular}

$\mathrm{P}>0.05$. 
Table-II: Comparative analysis of T lymphocyte subpopulations in two groups before the treatment $(\bar{X} \pm S) n=40$.

\begin{tabular}{|c|c|c|c|c|c|}
\hline Indicator & & Experimental Group $\Delta$ & Control Group $\Delta$ & $t$ & $p$ \\
\hline \multirow{4}{*}{$\mathrm{CD} 3+(\%)$} & Pre $^{*}$ & $40.57 \pm 8.25$ & $40.21 \pm 7.85$ & 0.91 & 0.37 \\
\hline & Post $\Delta$ & $48.64 \pm 9.73$ & $44.73 \pm 8.07$ & 2.45 & 0.02 \\
\hline & $\mathrm{t}$ & 4.00 & 2.54 & & \\
\hline & $\mathrm{p}$ & 0.00 & 0.01 & & \\
\hline \multirow{4}{*}{$\mathrm{CD} 4+(\%)$} & Pre $^{*}$ & $28.76 \pm 5.64$ & $28.54 \pm 6.49$ & 0.16 & 0.87 \\
\hline & Post $\Delta$ & $36.85 \pm 6.07$ & $32.91 \pm 6.33$ & 2.84 & 0.00 \\
\hline & $\mathrm{t}$ & 6.18 & 3.05 & & \\
\hline & $\mathrm{p}$ & 0.00 & 0.00 & & \\
\hline \multirow{4}{*}{$\mathrm{CD} 8+(\%)$} & Pre $^{*}$ & $20.55 \pm 3.57$ & $20.67 \pm 4.42$ & 0.13 & 0.89 \\
\hline & Post $\Delta$ & $21.87 \pm 4.35$ & $22.65 \pm 5.07$ & 0.74 & 0.46 \\
\hline & $t^{*}$ & 1.48 & 1.86 & & \\
\hline & $\mathrm{p}^{*}$ & 0.14 & 0.06 & & \\
\hline \multirow{4}{*}{$\mathrm{CD} 4+/ \mathrm{CD} 8+$} & Pre* & $1.25 \pm 0.35$ & $1.21 \pm 0.56$ & 0.38 & 0.70 \\
\hline & Post $\Delta$ & $1.56 \pm 0.21$ & $1.42 \pm 0.27$ & 2.58 & 0.01 \\
\hline & $\mathrm{t}$ & 4.80 & 2.14 & & \\
\hline & $\mathrm{p}$ & 0.00 & 0.04 & & \\
\hline
\end{tabular}

${ }^{*} \mathrm{p}>0.05, \Delta \mathrm{p}<0.05$.

Table-III: Comparative analysis of ECOG scores in two groups before and after the treatment $(\bar{X} \pm S) n=40$.

\begin{tabular}{lccc}
\hline Group & Improvement $^{*}$ & Stable & Deteriorating \\
\hline Experimental & 25 & 9 & 6 \\
Control & 18 & 14 & 8 \\
$X^{2}$ & 4.11 & 1.52 & 0.35 \\
$\mathrm{P}$ & 0.04 & 0.22 & 0.57 \\
\hline${ }^{*} \mathrm{p}<0.05$. & & &
\end{tabular}

conventional radiotherapy is $50-70 \%$. Insufficient local radiotherapy dosimetry in tumor volume may be the primary cause behind the failure of conventional radiotherapy..$^{18}$ Schild et $\mathrm{al}^{19}$ believed the radiotherapy among NSCLC patients obviously followed the dose-effect relationship, and thus raising radiotherapy dosimetry could directly improve the local control rate of tumor. Therefore, in present clinical lung cancer treatment, it is a usual practice to opt for a slightly higher dosage. ${ }^{20}$ In the meanwhile, higher dosage also brings in harm, dysfunction or even impaired function to peripheral organs. In severe cases, the patients' life quality may be greatly undermined and cannot continue with the treatment due to intolerance.

In order to improve the clinical control rate of NSCLC and reduce radiotherapy-incurred adverse reactions, some new radiotherapies are emerging in recent years. The IMRT, widely applied to the treatment of several tumors, is based on refined zoning of the target areas. During the radiotherapy, radiotherapy dose administered varies with the target area so as to protect normal tissues and raise the dosage to local tumor. ${ }^{21}$ According to Swanick et al. ${ }^{22}$, it could be radio-biologically speculated that

Table-IV: Comparative analysis of therapeutic effect in two groups $(\bar{X} \pm S) n=40$.

\begin{tabular}{lccccc}
\hline Group & $C R$ & $P R$ & $S D$ & $P D$ & Overall response rate $^{*}$ \\
\hline Experimental & 4 & 24 & 9 & 3 & $28(70 \%)$ \\
Control & 1 & 18 & 14 & 7 & $19(47.5 \%)$ \\
$X^{2}$ & & & & & 4.18 \\
$P$ & & & & & 0.04 \\
\hline
\end{tabular}

${ }^{*} \mathrm{P}<0.05$. 
Table-V: Comparative analysis of ADR in two groups $(\bar{X} \pm S) n=40$.

\begin{tabular}{lccccccc}
\hline Group & Anemia & Cough & Fever & $\begin{array}{c}\text { WBC } \\
\text { decrease }\end{array}$ & $\begin{array}{c}\text { Radiation } \\
\text { pneumonia }\end{array}$ & $\begin{array}{c}\text { Gastrointestinal } \\
\text { reaction }\end{array}$ & Occurrence $^{*}$ \\
\hline Experimental & 2 & 3 & 2 & 6 & 2 & 5 & $20(50 \%)$ \\
Control & 3 & 0 & 1 & 4 & 0 & 7 & $15(37.5 \%)$ \\
$X^{2}$ & & & & & & & 1.27 \\
$P$ & & & & & & & 0.26 \\
\hline
\end{tabular}

${ }^{*} \mathrm{p}>0.05$.

simultaneous modulated accelerated radiotherapy (SMART) could shorten the total treatment duration and improve tumor control rate and survival rate without further radioactively damaging the normal tissues. But Wang et al. ${ }^{23}$ recommended IMRT as a safe and effective way for treating locally advanced NSCLC patients, especially those present large mass or extensive lymphatic metastasis. In the opinion of Li et al. ${ }^{24}$ IMRT didn't differ much from conventional radiotherapy in terms of original tumor volume dose distribution, but it significantly lowered down the dose to adjacent organs and thus appeared less destructive to peripheral organs than conventional radiotherapy.

However, since the pathogenesis of lung cancer is affected by multiple factors, single treatment therapy can hardly take effect as expected. Thus, fewer cases are receiving radiotherapy alone. As such emerging novel means as immunotherapy and targeted therapy are more widely used in NSCLC treatment ${ }^{25}$, target drugs and immune drugs are recommended by more and more lung cancer diagnosis \& treatment guidelines for advanced NSCLC treatment. ${ }^{26} \mathrm{PD}-1$, an immune drug, is able to restore the immunity of cells via specifically blocking PD-1 suppression pathway and thus inhibits the tumor cells. ${ }^{27}$ As a programmed death receptor- 1 inhibitor, Camrelizumab is initially developed to cope with refractory lymphoma, but it turns out to be effective for NSCLC patients in some sense. ${ }^{28}$ Although programmed death 1 (PD-1)/programmed death ligand 1 (PD-L1) inhibitor has significantly altered the cancer therapies, advanced NSCLC patients largely remain unresponsive to PD-1/PD-L1 alone. ${ }^{29}$ The study of Wei et al. ${ }^{30}$ Indicated Camrelizumab combined with radiotherapy could improve the ORR of advanced NSCLC when compared with conventional radiotherapy.

As revealed by the findings of our study, IMRT combined with Camrelizumab surpasses IMRT alone in treating the locally advanced NSCLC patients. Firstly, combined therapy brings in improved immunity. After the treatment, the experimental group displayed significantly better improved $\mathrm{CD}^{+}, \mathrm{CD}^{+}$and $\mathrm{CD} 4^{+} / \mathrm{CD}^{+}$levels than the control group $\left(\mathrm{CD}^{+}, \mathrm{p}=0.02: \mathrm{CD}^{+}, \mathrm{p}=0.00\right.$ : $\left.\mathrm{CD}^{+} / \mathrm{CD}^{+}, \mathrm{p}=0.01\right)$. Secondly, it has witnessed a higher ORR which is $70 \%$ in the experimental group but $47.5 \%$ in the control group $(\mathrm{p}=0.03)$. Thirdly, the experimental group had significantly better physical status score improvement than the control group $(p=0.04)$. Finally, there is no significant rise in the ADR in the experimental group, as ADR in the experimental group is $50 \%$ and that in the control group is $37.5 \% \quad(p=0.26)$.

Taken together, IMRT combined with Camrelizumab appears efficient in treating the locally advanced NSCLC patients with significantly improved immunity and physical status but no higher ADR. Thus, the combined therapy is both safe and effective.

Limitations of the study: It includes small sample size and short follow-up period, thus it is impossible to evaluate the long-run prognosis of locally advanced NSCLC patients administered with IMRT combined with Camrelizumab as well as the benefits of improved immunity. We are proactively expanding the sample size and extending the follow-up period in the hope to provide a more objective evaluation of the combined therapy's efficacy in the long run.

Conflict of interest: The authors declare that there is no conflict of interest.

\section{Funding: None}

\section{REFERENCES}

1. Xian-Jun F, Xiu-Guang Q, Li Z, Hui F, Wan-Ling W, Dong L, et al. ERCC1 and BRCA1 mRNA expression predicts the clinical outcome of non-small cell lung cancer receiving platinum-based chemotherapy. Pak J Med Sci. 2014;30(3):488-492. doi: 10.12669/ pjms.303.4187 
2. Brown S, Banfill K, Aznar MC, Whitehurst P, Faivre Finn C. The evolving role of radiotherapy in non-small cell lung cancer. Br J Radiol. 2019;92(1104):20190524. doi: 10.1259/bjr.20190524

3. Baker S, Dahele M, Lagerwaard FJ, Senan S. A critical review of recent developments in radiotherapy for non-small cell lung cancer. Radiat Oncol. 2016;11(1):115. doi: 10.1186/s13014-016-0693-8

4. Diwanji TP, Mohindra P, Vyfhuis M, Snider JW 3rd, Kalavagunta $\mathrm{C}$, Mossahebi S, et al. Advances in radiotherapy techniques and delivery for non-small cell lung cancer: benefits of intensitymodulated radiation therapy, proton therapy, and stereotactic body radiation therapy. Transl Lung Cancer Res. 2017;6(2):131147. doi: 10.21037 /tlcr.2017.04.04

5. Yoon SM, Shaikh T, Hallman M. Therapeutic management options for stage III non-small cell lung cancer. World J Clin Oncol. 2017;8(1):1-20. doi: 10.5306/wjco.v8.i1.1

6. Arbour KC, Riely GJ. Systemic Therapy for Locally Advanced and Metastatic Non-Small Cell Lung Cancer: A Review. JAMA. 2019;322(8):764-774. doi: 10.1001/jama.2019.11058

7. Manjarrez-Orduno N, Menard LC, Kansal S, Fischer P, Kakrecha B, Jiang C, et al. Circulating T Cell Subpopulations Correlate With Immune Responses at the Tumor Site and Clinical Response to PD1 Inhibition in Non-Small Cell Lung Cancer. Front Immunol. 2018;9:1613. doi: 10.3389/ fimmu.2018.01613

8. Giatromanolaki A, Banham AH, Harris AL, Koukourakis MI. FOXP3 infiltrating lymphocyte density and PD-L1 expression in operable non-small cell lung carcinoma. Exp Lung Res. 2019;45(3-4):76-83. doi: 10.1080/01902148.2019.1617371

9. da Cunha Santos G, Shepherd FA, Tsao MS. EGFR mutations and lung cancer. Annu Rev Pathol. 2011;6:49-69. doi: 10.1146/ annurev-pathol-011110-130206

10. Jonna S, Subramaniam DS. Molecular diagnostics and targeted therapies in non-small cell lung cancer (NSCLC): an update. Discov Med. 2019;27(148):167-170.

11. Balata H, Fong KM, Hendriks LE, Lam S, Ostroff JS, Peled N, et al. Prevention and Early Detection for NSCLC: Advances in Thoracic Oncology 2018. J Thorac Oncol. 2019;14(9):1513-1527. doi:10.1016/j.jtho.2019.06.011

12. Chun SG, Hu C, Choy H, Komaki RU, Timmerman RD, Schild $\mathrm{SE}$, et al. Impact of Intensity-Modulated Radiation Therapy Technique for Locally Advanced Non-Small-Cell Lung Cancer: A Secondary Analysis of the NRG Oncology RTOG 0617 Randomized Clinical Trial. J Clin Oncol. 2017;35(1):56-62. doi: 10.1200/JCO.2016.69.1378

13. Pollom EL, Qian Y, Durkee BY, von Eyben R, Maxim PG, Shultz DB, et al. Hypofractionated Intensity-Modulated Radiotherapy for Patients With Non-Small-Cell Lung Cancer. Clin Lung Cancer. 2016;17(6):588-594. doi: 10.1016/j.cllc.2016.05.024

14. Lalchandani UR, Sahai V, Hersberger K, Francis IR, Wasnik AP. A Radiologist's Guide to Response Evaluation Criteria in Solid Tumors. Curr Probl Diagn Radiol. 2019;48(6):576-585. doi 10.1067/j.cpradiol.2018.07.016

15. Young J, Badgery-Parker T, Dobbins T, Jorgensen M, Gibbs $\mathrm{P}$ Faragher I, et al. Comparison of ECOG/WHO performance status and ASA score as a measure of functional status. J Pain Symptom Manage. 2015;49(2):258-264. doi: 10.1016/j.jpainsymman.2014.06.006

16. Mesko S, Gomez D. Proton Therapy in Non-small Cell Lung Cancer. Curr Treat Options Oncol. 2018;19(12):76. doi: 10.1007/ s11864-018-0588-z

17. Wanet M, Delor A, Hanin FX, Ghaye B, Van Maanen A, Remouchamps V, et al. An individualized radiation dose escalation trial in non-small cell lung cancer based on FDG-PET imaging. Studie zur individualisierten Bestrahlungsdosiseskalation be nichtkleinzelligem Lungenkarzinom basierend auf der FDGPET-Bildgebung. Strahlenther Onkol. 2017;193(10):812-822. doi $10.1007 / \mathrm{s} 00066-017-1168-\mathrm{z}$

18. Fondevilla Soler A, Lopez-Guerra JL, Dzugashvili M, Sempere Rincon $\mathrm{P}$, Sautbaet A, Castañeda P, et al. Outcome and toxicity of intensity modulated radiotherapy with simultaneous integrated boost in locally advanced non-small cell lung cancer patients. Clin Transl Oncol. 2017;19(12):1469-1477. doi: 10.1007/ s12094-017-1689-z
19. Schild SE, Hillman SL, Tan AD, Ross HJ, McGinnis WL, Garces YA, et al. Long-Term Results of a Trial of Concurrent Chemotherapy and Escalating Doses of Radiation for Unresectable Non-Small Cell Lung Cancer: NCCTG N0028 (Alliance). J Thorac Oncol. 2017;12(4):697-703. doi: 10.1016/j. jtho.2016.12.021

20. Xu Y, Zheng X, Bai X, Li P, Ma H, Wang J, et al. Simultaneous integrated boost intensity-modulated radiotherapy for locally advanced non-small cell lung cancer in Chinese population: A retrospective study. Oncotarget. 2017;8(30):49084-49092. doi: 10.18632/oncotarget.17094

21. Yegya-Raman N, Zou W, Nie K, Malhotra J, Jabbour SK Advanced radiation techniques for locally advanced non-small cell lung cancer: intensity-modulated radiation therapy and proton therapy. J Thorac Dis. 2018;10(Suppl 21):S2474-S2491. doi: $10.21037 /$ jtd.2018.07.29

22. Swanick CW, Lin SH, Sutton J, Naik NS, Allen PK, Levy LB, et al. Use of simultaneous radiation boost achieves high control rates in patients with non-small-cell lung cancer who are not candidates for surgery or conventional chemoradiation. Clin Lung Cancer. 2015;16(2):156-163. doi: 10.1016/j.cllc.2014.10.005

23. Wang D, Bi N, Zhang T, Zhou Z, Xiao Z, Liang J, et al. Comparison of efficacy and safety between simultaneous integrated boost intensity-modulated radiotherapy and conventional intensitymodulated radiotherapy in locally advanced non-small-cell lung cancer: a retrospective study. Radiat Oncol. 2019;14(1):106. doi: 10.1186/ s13014-019-1259-3

24. Li H, Xu D, Han X, Ruan Q, Zhang X, Mi Y, et al. Dosimetry study of 18F-FMISO+PET/CT hypoxia imaging guidance on intensity-modulated radiation therapy for non-small cell lung cancer. Clin Transl Oncol. 2018;20(10):1329-1336. doi: 10.1007/ s12094-018-1864-x.

25. Itonaga $T$, Mikami R, Nakayama $H$, Saito $T$, Shiraishi $S$, Okubo M, et al. Phase II study of compensator-based noncoplanar intensity-modulated radiotherapy for Stage I nonsmall-cell lung cancer. J Radiat Res. 2019;60(3):387-393. doi: $10.1093 / \mathrm{jrr} / \mathrm{rrz} 009$

26. Osmani L, Askin F, Gabrielson E, Li QK. Current WHO guidelines and the critical role of immunohistochemical markers in the subclassification of non-small cell lung carcinoma (NSCLC): Moving from targeted therapy to immunotherapy. Semin Cancer Biol. 2018;52(Pt-1):103-109. doi: 10.1016/j.semcancer.2017.11.019

27. Giatromanolaki A, Banham AH, Harris AL, Koukourakis MI. FOXP3 infiltrating lymphocyte density and PD-L1 expression in operable non-small cell lung carcinoma. Exp Lung Res. 2019;45(3-4):76-83. doi: 10.1080/01902148.2019.1617371

28. Wei Z, Yang X, Ye X. Rechallenge of camrelizumab in non-smallcell lung cancer patients treated previously with camrelizumab and microwave ablation. J Cancer Res Ther. 2020;16(5):11911195. doi: 10.4103/jcrt.JCRT_798_20

29. Yan X, Zhao Y, Liu Y, Yang Q, Dong L, Wu Z, et al. Case Report: Low-Dose Decitabine Plus Anti-PD-1 Inhibitor Camrelizumab for Previously Treated Advanced Metastatic Non-Small Cell Lung Cancer. Front Oncol. 2020;10:558572. doi: 10.3389/ fonc. 2020.558572

30. Wei Z, Yang X, Ye X, Huang G, Li W, Han X, et al. Camrelizumab combined with microwave ablation improves the objective response rate in advanced non-small cell lung cancer. J Cancer Res Ther. 2019;15(7):1629-1634. doi: 10.4103/jcrt.JCRT_990_19

\section{Authors' Contributions:}

Jun-kai $\mathbf{X u}$ designed this study and prepared this manuscript, collected and analyzed clinical data. $\mathrm{He}$ is responsible and accountable for the accuracy or integrity of the work 